\title{
RECENT RESEARCH TOPICS IN HIGH-LIFT AERODYNAMICS
}

\author{
J. Wild, \\ DLR Institute for Aerodynamics and Flow Technology, \\ Lilienthalplatz 7, 38108 Braunschweig, Germany
}

\begin{abstract}
High-lift systems are matured, robust and reliable components of a transport aircraft. Although facing nearly 100 years of history, there is an ongoing need of research in the aerodynamics of such systems due to changes in the requirements for aircraft development. Other than in former times, high-lift aerodynamics research is nowadays more incorporated into larger projects. It is therefore not as visible as before when dedicated high-lift projects were conducted, as e.g. the EC funded project EUROLIFT.

The aim of this summary is to collect from different projects the current challenging research topics in the area of highlift aerodynamics. The contribution gives an overview on recent research topics addressed at the German DLR Institute of Aerodynamics and Flow Technology in collaboration with national and international partners.
\end{abstract}




\section{Introduction}

To obtain reasonable low flight speeds at take-off, approach and landing is one of the key capabilities for safe flying vehicles. This key observation is nearly as old as man's flight by itself. One would therefore expect that measures for lift augmentation are well known, understood and matured. So, the main question is where there is the need of further research

In fact, for the above objective the augmentation of the maximum achievable lift coefficient is the major target, which is closely related to the prevention of flow separation. Already 1904 Ludwig Prandtl [1] introduced active suction as a probable mean to achieve this - at the same time when formulating the foundation of boundary layer theory. Active flow separation control is therefore an older technology than any passive lift augmentation device.

Looking into history, we have to admit that any passive technology to increase the maximum lift coefficient has been invented latest 60 years ago. As early as 1914 Nayler, Stedman and Stern [2] experimented with an airfoil of variable camber. Gustav Lachmann [3] and Frederic Handley Page [4] invented independently the leading edge slat in 1917. William D. Fowler [5] invented the basics for all todays flying single- and multi-slotted trailing edge devices in 1927. The droop-nose - today flying on the Airbus A350 and A380 inboard wings - origins back to Ludwig Bölkow in 1939 [6]. And even the youngest principle of the leading edge split flap by Werner Krüger dates back to 1943 [7]. Any highlift system in service today is a successor of one of these concepts.

Although all these concepts worked in the expected way, the physical understanding stayed quite limited up to the famous speech of A.M.O Smith [8] in 1972. But even nowadays high-lift systems are often associated with boundary layer control dating back to Prandtl's original work. Some aspects of Smith's five effects on slotted airfoils were already reported earlier.But overall, it took 60 years to summarize the physical effects occurring at multi-element airfoils.

Now, 40 years past Smith's publication, one can say that high-lift systems are well matured. In the younger past, research effort has been more put on the design methods and making use of modern analysis methods like computational fluid dynamics (CFD). And still, a major topic of research is the validation of simulation methods. especially for the stall region, where turbulence modelling is a key for proper prediction of separation onset. For the development of high-lift systems only few improvements are expected. The design nowadays is heavily driven by multi-disciplinary constraints from structures and systems.

But, there are new challenges arising to aircraft development resulting from a changed perception of air transportation within the society. Within the past two decades especially environmental concerns have entered into the focus. Aircraft manufactures today are strongly asked to react on these issues. The most visible recommendations for development paths in European aircraft industry are summarized in the ACARE Vision 2020 [9] and Flightpath 2050 [10] documents guiding research funding within Europe. The major topics with impact on the high-lift system include $\mathrm{CO}_{2}$ emission, aircraft noise perception, low environmental footprint in terms of resource awareness, and cost awareness for affordable air transport.

In consequence, the current high-lift system layout is probably not suited to achieve new technology steps to address these challenges, as there are laminar wing technology, airframe noise reduction (elimination of slat noise), and simplified moveable layouts (multi-functional control surfaces). The high-lift system is asked to strongly contribute to the realization of these new technologies. Consequently, the new need for high-lift system research focusses on contributing to the realization, sometimes by direct improvements, sometimes by enabling other beneficial technologies. The aim of this contribution is to highlight and summarize ongoing research efforts to address these new challenges in high-lift system aerodynamic design, currently performed at the DLR Institute of Aerodynamics and Flow Technology. As these research efforts aim to deliver also matured technologies, they are performed in international cooperation with other research institutes, industry and academia. The research presented ranges from methods driven topics like CFD validation, multi-disciplinary optimization and design, to design and application including laminar wing high-lift systems, noise reduction, active flow control, adaptive structures, and multi-functional movables.

\section{Design and Analysis Methods}

Computational Fluid Dynamics (CFD) based on solving the Reynolds-averaged Navier-Stokes (RANS) equations has evolved to a standard tool in aerodynamic design and analysis. The robustness and accuracy of such methods have improved to make it a reliable tool for aerodynamics engineers today.

Nevertheless, for high-lift system aerodynamics the proper prediction of stall onset is still a challenge for these methods. The $2^{\text {nd }}$ AIAA High-Lift prediction workshop [11] - an initiative to summarize and compare CFD based predictions of current state-of-the-art flow solvers in order to detect strengths and weaknesses of the general approach and to improve the reliability - again identified two major building bricks of CFD simulation to currently focus on for improving the prediction capabilities, namely the meshing and the turbulence modelling.

All the verification and validation efforts need a database that reliably reflects the situation on the aircraft. For this purpose DLR has coordinated the national funded initiative HINVA to gather and compare aerodynamic data at extreme high-lift conditions at stall obtained by CFD, wind tunnel experiment, and real flight tests [12]. 


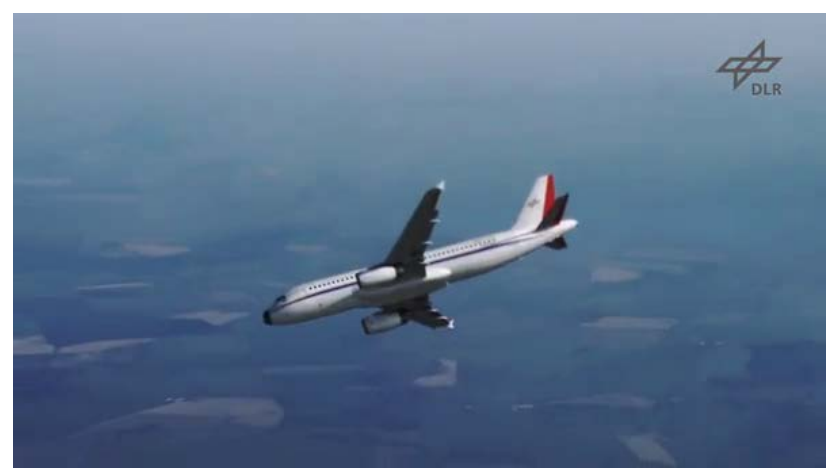

Fig. 1: DLR research aircraft ATRA diving just past stall (image extracted from [13]).

A descent highlight of the project was to perform two flight test campaigns with the DLR A320-232 ATRA research aircraft heavily instrumented for aerodynamic measurements performing stall maneuvers (Fig. 1). In parallel high effort has been taken to simulate the flow of the real aircraft geometry by high Reynolds number wind tunnel testing [14] and CFD simulation [15].

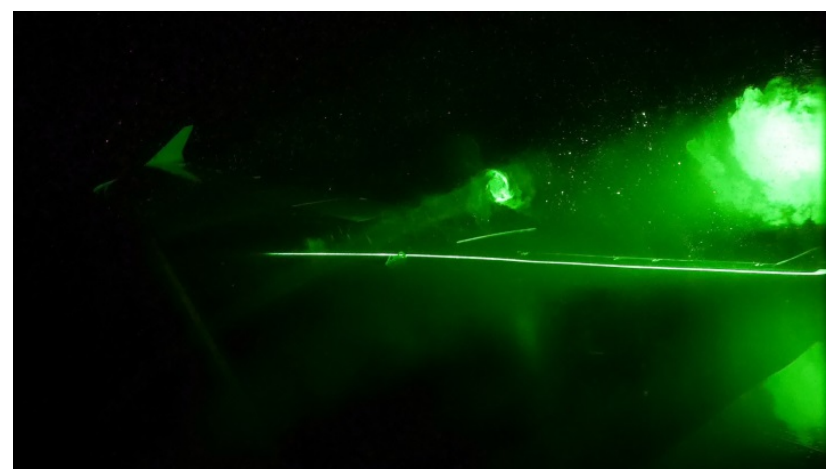

Fig. 2: Application of in-flight PIV to trace vortices close to stall conditions (image: www.dlr.de).

With this unique database it will be possible to mature simulation techniques further in order to achieve a next step in simulation accuracy and prediction reliability. Especially the information gained from detailed flow measurements including first-time used in-flight PIV (Fig. 2) will help to validate the simulation methods towards a more reliable design tool especially in the area of stall onset. The data analysis of the flight tests is still ongoing and final results are expected in near future.

\section{High-Lift Systems for Laminar Wings}

A key contribution to fuel reduction is commonly seen in the use of laminar wing technology. It is expected to be the only single technology to provide up to $10 \%$ drag reduction and a corresponding $5 \%$ lower fuel burn. While this technology is posing challenges for wing manufacturing, also for high-lift systems new types of devices have to be found - especially at the leading edge to avoid surface imperfections on the upper side.

\subsection{Natural laminar flow wings}

In the frame of the EC funded and DLR coordinated project DeSiReH (2009-2013) [16] several high-lift system concepts were analyzed for their compatibility with the requirements of natural laminar flow (NLF) wing integration. The final leading edge device proposed is a successor of the vented Krueger concept already used in the Boeing HLFC test program on a B757 aircraft [17]. Although giving up laminar flow of the lower wing surface, this type of Krueger device is the sole system that offers the additional functionality of shielding the laminar wing against contamination by insects or similar.

The major contribution of the work performed was taking into account all the requirements and using numerical optimization directly for this purpose. The requirement for contamination shielding has been directly incorporated in the parameterization of the geometry (Fig. 3). This results in a guaranteed shielding property for all generated instances during optimization. Limitations resulting from the mechanical integration have been respected by applying the designated kinematics type throughout the design process. 


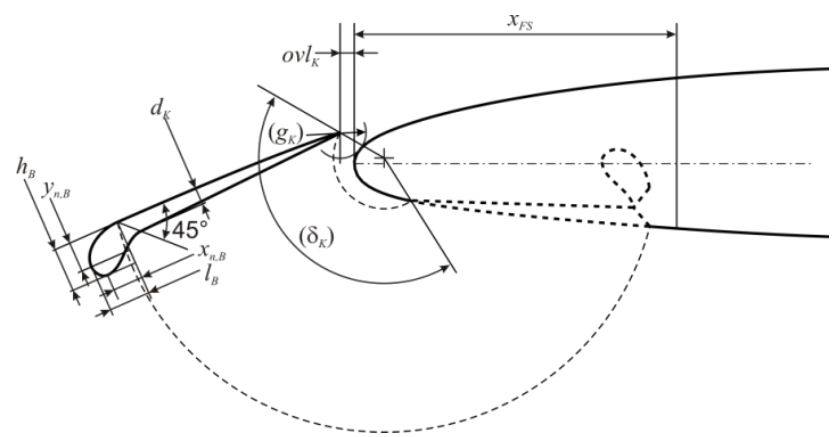

Fig. 3: Parameterization of the vented folding bull-nose leading edge device concept (image from [16]).

After performing full 3D optimization, the final high-lift configuration of a low sweep NLF wing was properly scaled and incorporated into the DLR-F11 wind tunnel model and tested at flight Reynolds numbers in the European Transonic Windtunnel (ETW) facility (Fig. 4). The original model was equipped with a classical high sweep turbulent high-lift wing and was tested within the EC funded projects EUROLIFT I and II [18]. The comparison of the high-lift performance in terms of lift coefficient over angle of attack (Fig. 5) shows a quite similar maximum lift coefficient. The Krueger based high-lift system obtains its lift at slightly lower angles of attack.

In the scope of the project, a final assessment on aircraft level revealed a 3\%-7\% potential of fuel burn saving compared to a turbulent wing design for the same mission. The designed high-lift system contributed to this result by its high maximum lift coefficient avoiding a wing area increase for compensation of maximum lift loss.

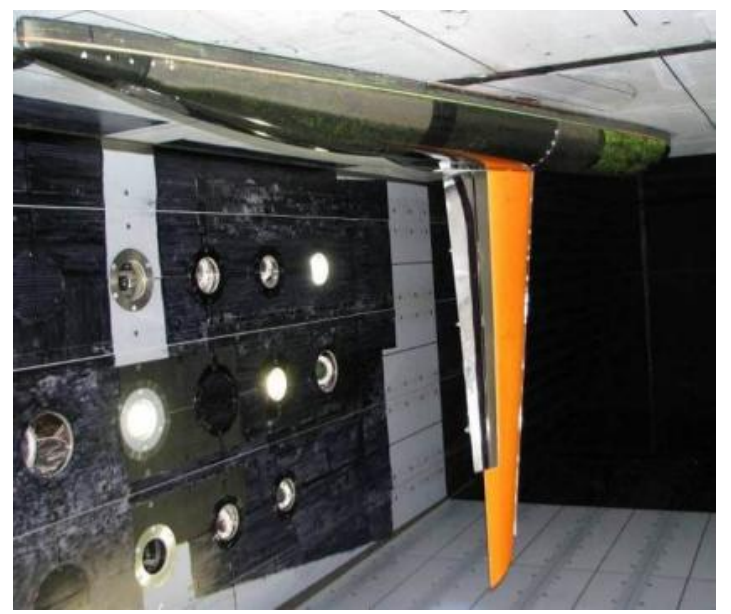

Fig. 4: DLR-F11 high-lift model equipped with laminar wing high-lift system (DS21) in the test section of the ETW (image from [16]). 


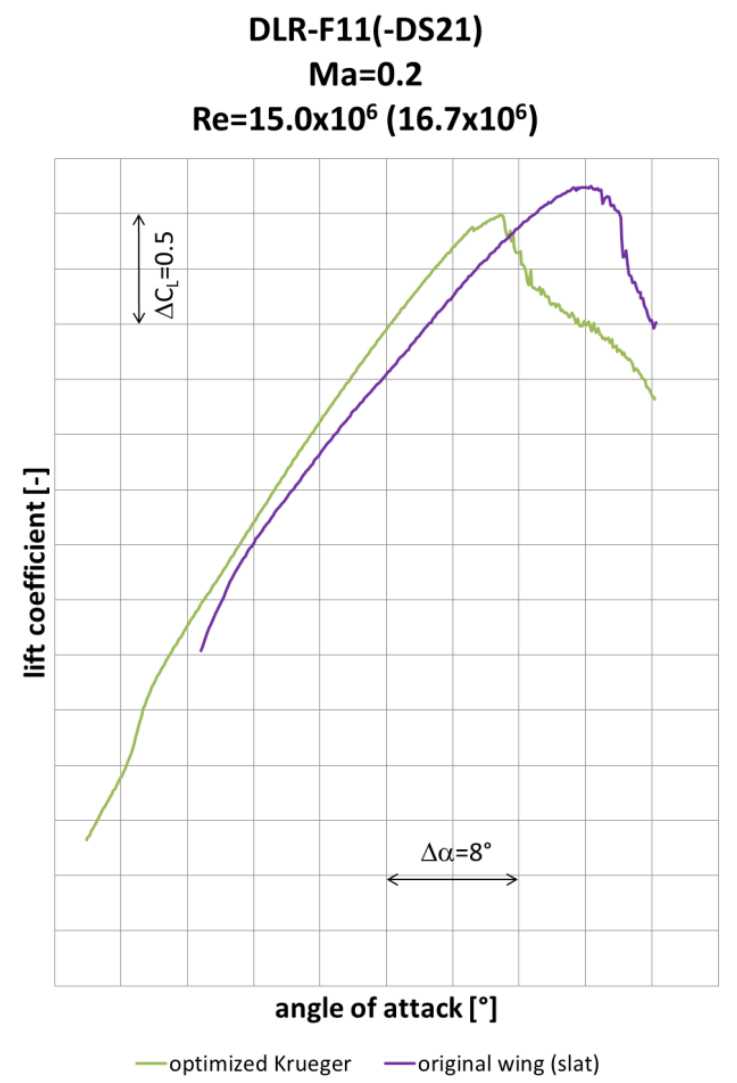

Fig. 5: High-lift performance comparison of laminar wing high-lift wing and turbulent high-lift wing at the DLR-F11 high-lift at flight Reynolds number (image from [16]).

\subsection{Hybrid Laminar Flow Control Wings}

Integration of a Krueger device into a wing leading edge for hybrid laminar flow control (HLFC) faces different requirements, while the general functionality requests on high performance and shielding properties remain. The airfoil shape of an airfoil for HLFC has a bigger leading edge radius and is there in general thicker than for NLF. But the wing integration for the interior is more challenging. due to the number of additional systems for the suction system for HLFC.

Within the current EC funded project AFLoNext [19], a full integration study is performed for integrating a complete HLFC system together with the Krueger device into an outboard portion of an HLFC wing (Fig. 6) [20].

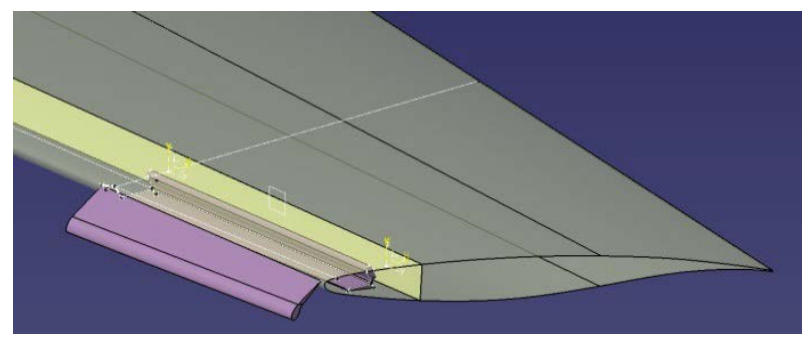

Fig. 6: Aerodynamic design of the Krueger device at an outboard HLFC wing shape (image from [20]).

In addition to the studies performed on the NLF wing before, now the complete specific design including system integration is done. Space allocation has turned out to be a very crucial issue, especially due to the additional space needed by the HLFC system which makes the interior of the wing leading edge extremely crowded (Fig. 7). The realization of the Krueger system is achieved in close cooperation with partners caring about the detailed designs of the Krueger panel structure (INVENT GmbH) and the kinematics (ASCO N.V.). 


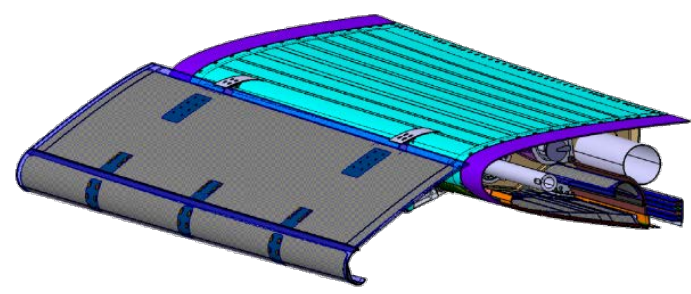

Fig. 7: 3D full system integration of the Krueger into an outboard HLFC wing leading edge (image from [20]).

The aerodynamic design [21] - again compared to a classical slat design (Fig. 8), but now on the same wing shape reveals again a loss of maximum lift coefficient but this time a gain in drag coefficient for the nearly complete range of incidences within the operational regime. It should be noted that the loss in lift is mainly related to the space allocation limiting the feasible size of the Krueger device, while the size of the reference slat was not limited by additional system constraints.

The integrated leading edge will undergo testing of aerodynamics and systems in the further scope of the project. Nevertheless, the performed studies already now reveal that a Krueger device can be designed for very high aerodynamic performance while still respecting the special needs resulting from laminar wing applications. But even for standard wings such a concept can have benefits in terms of drag and even system weight.

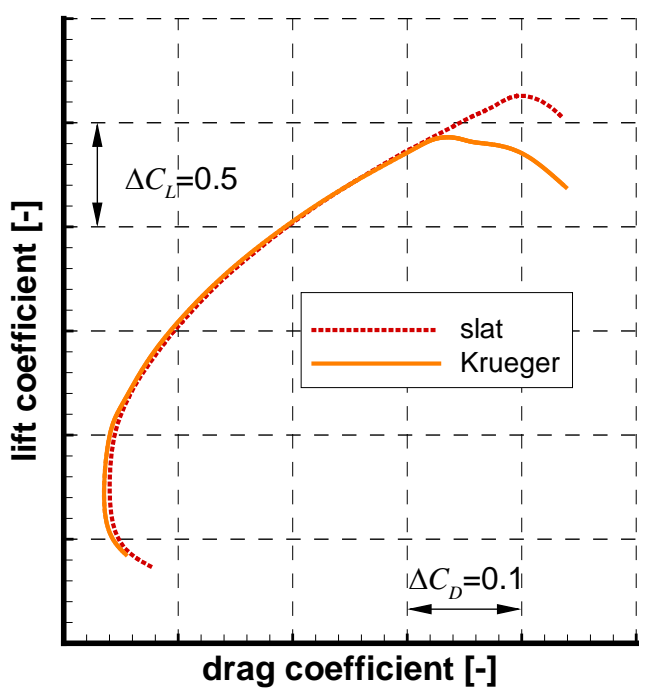

Fig. 8: High-lift performance comparison of Kruger and slat device on a HLFC wing shape (image from [21]).

\section{Noise Reduced High-Lift Systems}

Aircraft noise is of growing interest due to the global increase of air transportation. Facing the additional growth of urban areas, airports formerly located far off are today adjacent to highly populated areas. Also the aircraft industry has to put high efforts in keeping the impact on the public as low as feasible to guarantee the acceptance of air transportation.

Past research has revealed that the noise generated by deflected high-lift systems is one of the major contributors to the airframe noise [22]. It is significant especially for incoming aircraft. Within the high lift system the slat trailing edge is one major source of noise generation. On the other hand, the design of the slat and especially the positioning is very crucial to aerodynamic high-lift performance. And noise reduction has no significant value on its own in terms of aircraft operating cost, at least for large transport airplanes. It is therefore always on lower priority than performance. Therefore, any measure of noise source reduction at the slat has to be counterbalanced with its aerodynamic effect to improve the perception of noise on the ground. Lower aerodynamic performance is at the end reflected in a higher flight speed, which is itself a dominant parameter of noise generation.

\subsection{Very Long Chord Slat}

Aside attempts to reposition the slat for lower noise foot print, changed leading edge device concepts are necessary to achieve net benefits. One concept for this is the very long chord slat (VLCS) concept [23]. The concept is based on the 
finding that the generated trailing edge sound intensity scales with the local trailing edge velocity by 4.5 [22].

Positioning the slat trailing edge into a region of less local flow velocity is suitable to reduce the generated noise substantially. To recover the aerodynamic performance the slat is increased in size and deflected less steep (Fig. 9).

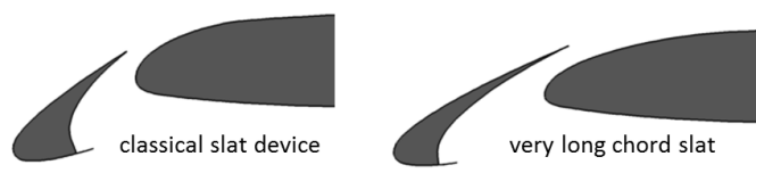

Fig. 9: The very long chord slat (VLCS) - a concept to reduce slat trailing edge noise at comparable aerodynamic performance.

In the frame of the DLR project „Leiser Start und Anflug“ (LEISA) such a VLCS device was designed and tested based on the two-dimensional DLR-F15 high-lift airfoil [23]. Within the series of experimental test campaigns - including high Reynolds number aerodynamic tests and aeroacoustics tests - a broadband noise reduction of about $5 \mathrm{~dB}$ at similar aerodynamic performance was verified (Fig. 10). Comparisons to a fully retracted slat configuration displayed at the same time an overall 8dB broadband noise reduction potential to be saved by completely eliminating the slat as a noise source but at highly degraded aerodynamics. The VLCS device is therefore capable to eliminate $50 \%$ of the slat generated noise.

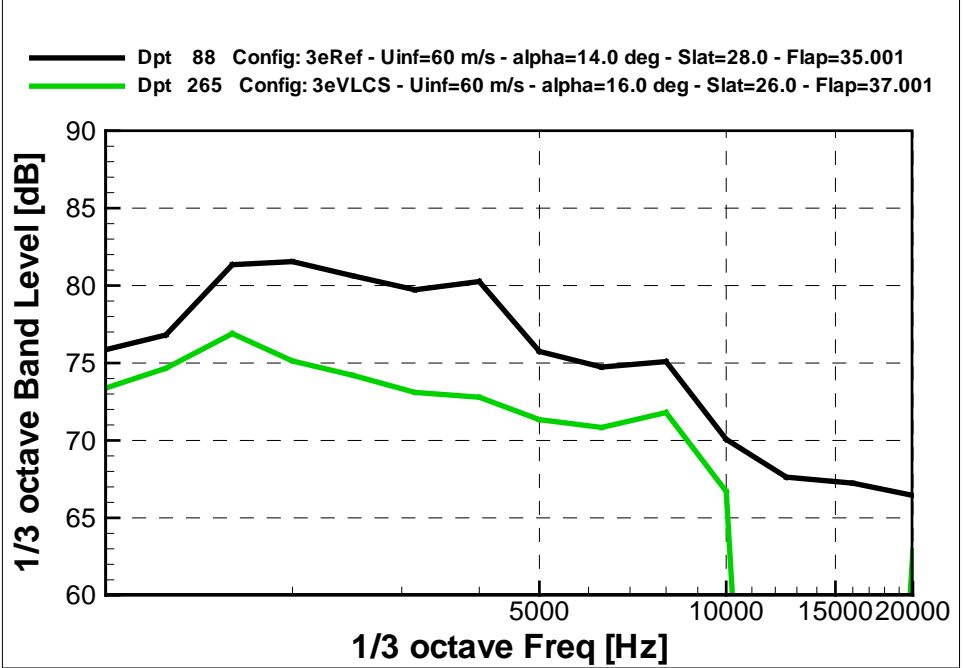

Fig. 10: Noise levels from array measurements for standard slat and VLCS device at same aerodynamic performance.

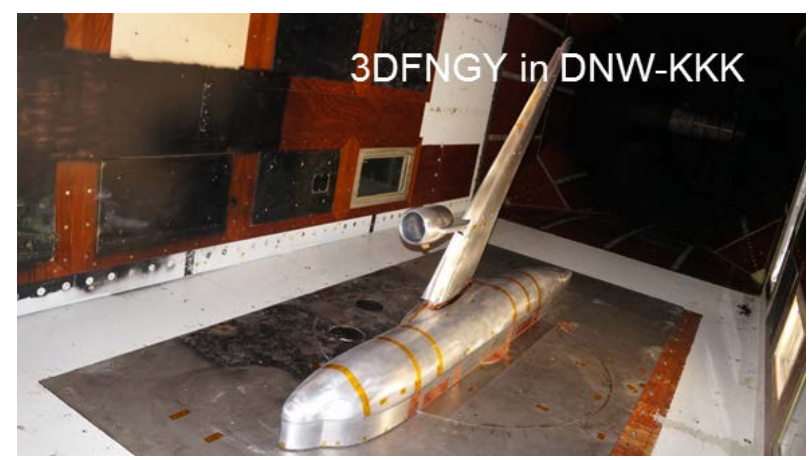

Fig. 11: The very long chord slat (VLCS) applied to 3D half model installed in the DNW-KKK cryogenic wind tunnel for testing at higher Reynolds number (image from [24]).

Within the DLR-internal project “Silent Leading Edge Devices” (SLED) [24] the concept has recently been applied to a full three-dimensional half model configuration (Fig. 11). The tests verified the noise reduction potential of the VLCS configuration from the previous two-dimensional investigations. But also the aerodynamic performance was verified to be achieved even at higher Reynolds numbers. As a main difference to the classical slat the levels of lift coefficient are mainly achieved at an about $2^{\circ}$ lower angle of attack (Fig. 12). 


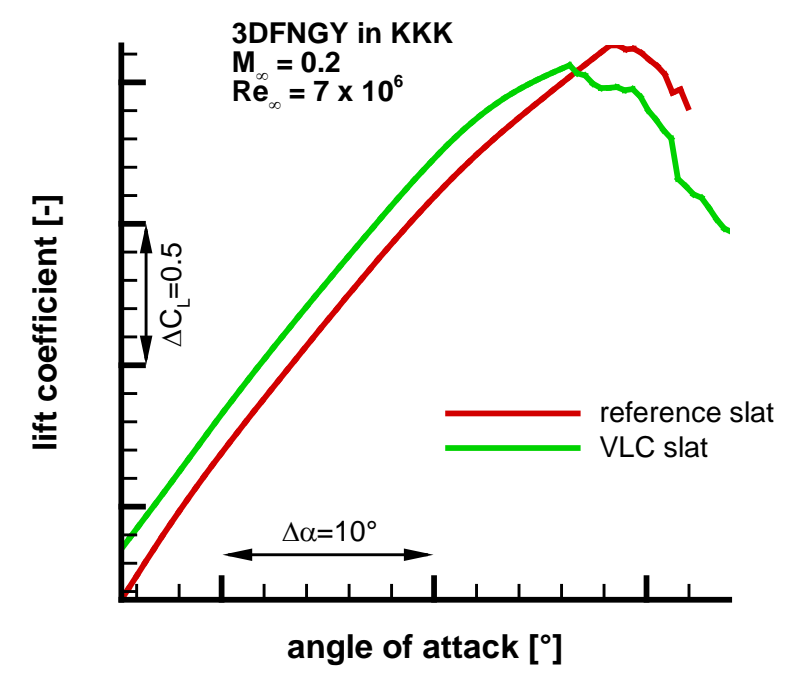

Fig. 12: Comparison of lift coefficient vs. angle of attack of a classic slat and a VLCS device for the 3D half model at higher Reynolds number (image from [24]).

Next steps of maturing this device would necessarily lead to full flight tests of such a device to demonstrate the noise reduction potential on aircraft level in fly-over measurements. Such investigation still needs a lot of prior work and is currently in planning for future projects.

\subsection{Smart Leading Edge Device}

The smart deforming droop nose is another concept originally intended for noise reduction at the leading edge. Since no gap is existent, the noise of the leading edge system is completely vanished. From early research it had already been known that rigid droop nose devices largely fail to achieve high lift performances at levels known from slat devices. Mainly the appearing kink in the upper surface limits the stall angle of the airfoil.

With the smart droop nose it is expected to shift the stall limit more close to the slat device, even though it is known from theory that the lift values of slotted leading edge systems are not attainable. But even here the question of the counterbalancing of noise reduction and performance drop had been to be analyzed before a statement of feasibility. The concept itself has already been invented as the REAVAM leading edge in the late 60's [25][26]. Today's improvements of material technology make this concept getting more feasible.

A key issue to a feasible aerodynamic design hereby is to deform the shape taking into account a constant arc length of the leading edge surface to avoid high strain within the heavily loaded surface (Fig. 13). With the help of CFD such a smart leading edge has been designed [27][28], built at full scale, and wind tunnel tested within the frame of the EC funded project SADE [29].

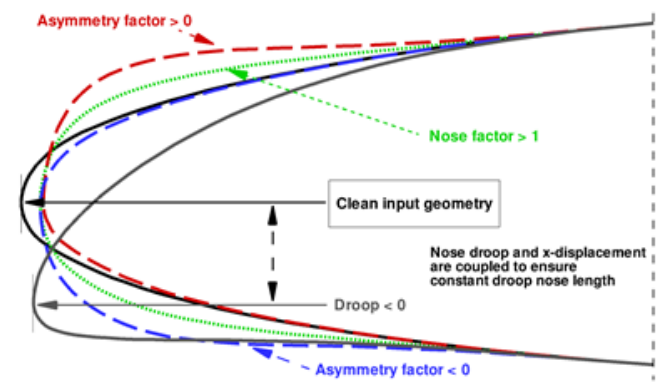

Fig. 13: Smooth variation of the leading edge in the sense of a smart droop nose exhibiting no change in arc length (image from [27]).

The essential achievement of these measurements was to analyze the shape of the bended wing leading edge under the aerial loading by the wind forces. It is clear that deformability and strength have to be traded off for such a device. The measurements unveiled that a design method not taking into account the flow forces for structure design leads to unintended waviness of the surface recognizable in the local pressure distribution (Fig. 14). 

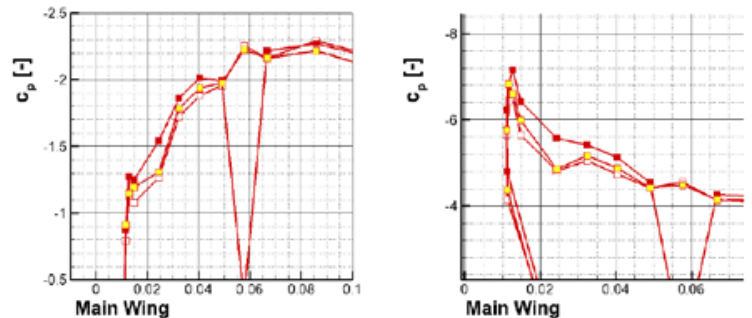

Fig. 14: Measured deformation and pressure distribution of a deflected smart leading edge under wind load (images from [29]).

Although the major maturation is now dedicated to the improved structural design, the aerodynamic behavior offers additional applications than for noise reduction. For laminar wings the gapless concept offers potential for additionally keeping the lower surface laminar in contrast to the above mentioned Krueger device. Such a concept in conjunction with a circulation control flap is e.g. followed for an extremely short take-off and landing aircraft within the frame of the SFB880 activities [30].

\section{Active Flow Separation Control}

Despite active flow control (AFC) for separation suppression is as old as boundary layer theory itself [1], it hasn't found its application in civil transport aircraft design up to now. Only in military aircraft some attempts have been made, more or less successfully. A reason for this may be seen in the more stringent requirements in terms of efficiency, reliability and robustness. And, critically seen, AFC as replacement for high-lift systems up to now has failed to demonstrate highlift performance benefits compared to well-designed passive devices.

Nevertheless, fluid dynamic research on AFC has been ongoing - mainly at academia and research establishments - to mature the efficiency and robustness and to alleviate potential risks from Reynolds number, Mach number and sweep effects [31]. Up to five years ago most activities focused full wing applications and were mainly based on twodimensional airfoil studies. Nowadays, it's getting more interesting to recover only parts of the flow. Especially areas of interest are those, where passive high-lift devices are not feasible. Two regions of the wing are currently identified to be improved by AFC technology.

\subsection{AFC at Curved Wingtips}

The installation of aggressively for cruise performance optimized curved wingtip shapes concepts poses new challenges at the high-lift configuration. Those wingtips don't allow the installation of classical high-lift devices at the leading edge. They are therefore prown to early separation onset in low speed conditions. In the national funded project MOVE.ON, such a wingtip with installed AFC at the leading edge to prevent early wing tip stall was investigated in detail by numerical simulations [32] and experiments [33].

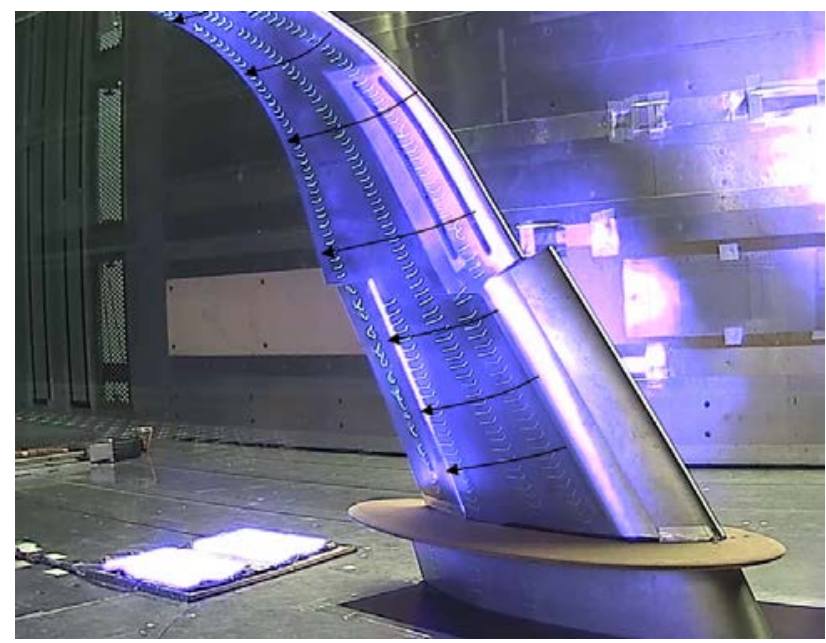

Fig. 15: Outer Wing Model tested with AFC in the DNW-NWB facility (image from [33]).

The investigated geometry is reduced to the very outboard part of a modern transport aircraft wing, but still including the last portion of the slat device. AFC was incorporated outboard of the slat end (Fig. 15). Within the project it was able to demonstrate that attached flow on the wing tip can be achieved for up to $2.5^{\circ}$ more incidence (Fig. 16) at mass 
flow rates within the very strict requirement targets from industry.

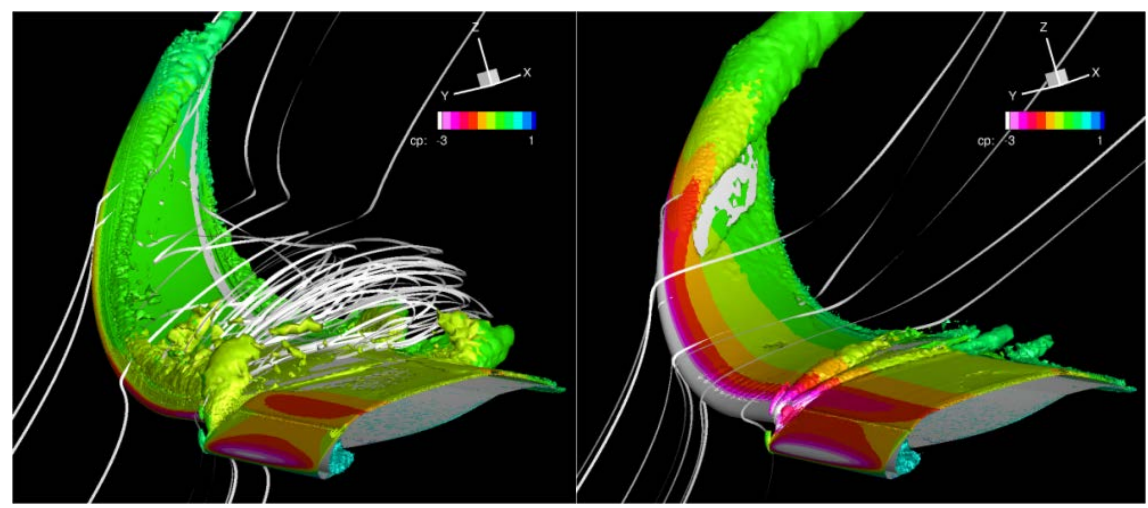

Fig. 16: Preventing stall on the wing tip device at high angles of attack (separation onset $+1^{\circ}$ ): $($ left) without AFC; (right) with AFC (image from [32]).

\subsection{AFC at the Wing / Engine Junction}

The trend to larger engines for fuel reduction impacts the high-lift design in case of under-wing mounted engines detrimentally. In order to avoid collision of the slat and the engine, the cut-back of the slat increases in the same way as the diameter of the engine. Additionally, since also ground clearance of the engine can get an issue, these engines tend to be more closely coupled to the wing, which again increases the reduction of slat span.

The area downstream the unprotected leading edge is known to be at risk of flow separation, which can limit the overall high-lift performance. AFC is assumed to be a technology that can be applied here to mitigate this negative impact of increasing the engine size (Fig. 17).

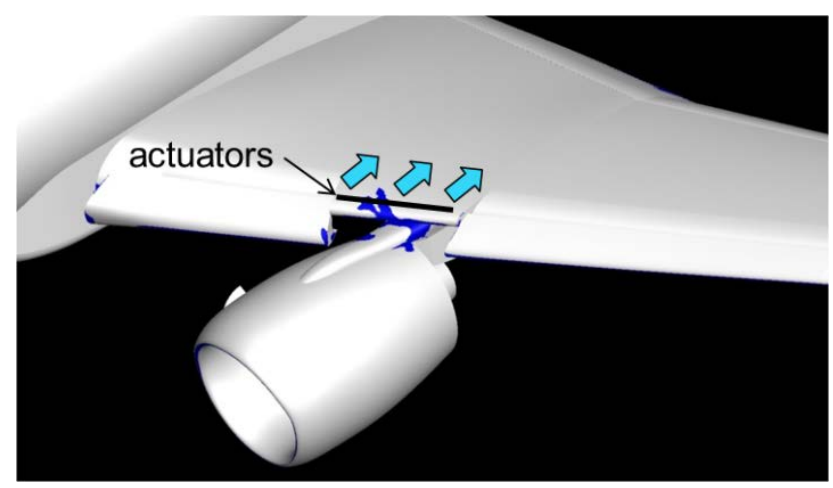

Fig. 17: Large engine installed underneath the wing, requiring large slat cut-out (image from [34]).

Within the EC funded project AFLoNext [19] an attempt is made to use AFC here and to design and demonstrate at full scale its ability and feasibility to improve the high-lift performance. Fig. 18 shows the result of the numerical design of the needed actuation for alternating pulsed blowing actuators [34]. The images are instantaneous snapshots of unsteady time-resolved simulations. The marked areas indicate a flow reversal regarding the onflow direction indicating separated flow. As seen, the pulsed blowing AFC design is able to prevent flow separation in a time averaged sense already at jet velocities significantly below sonic speed. 


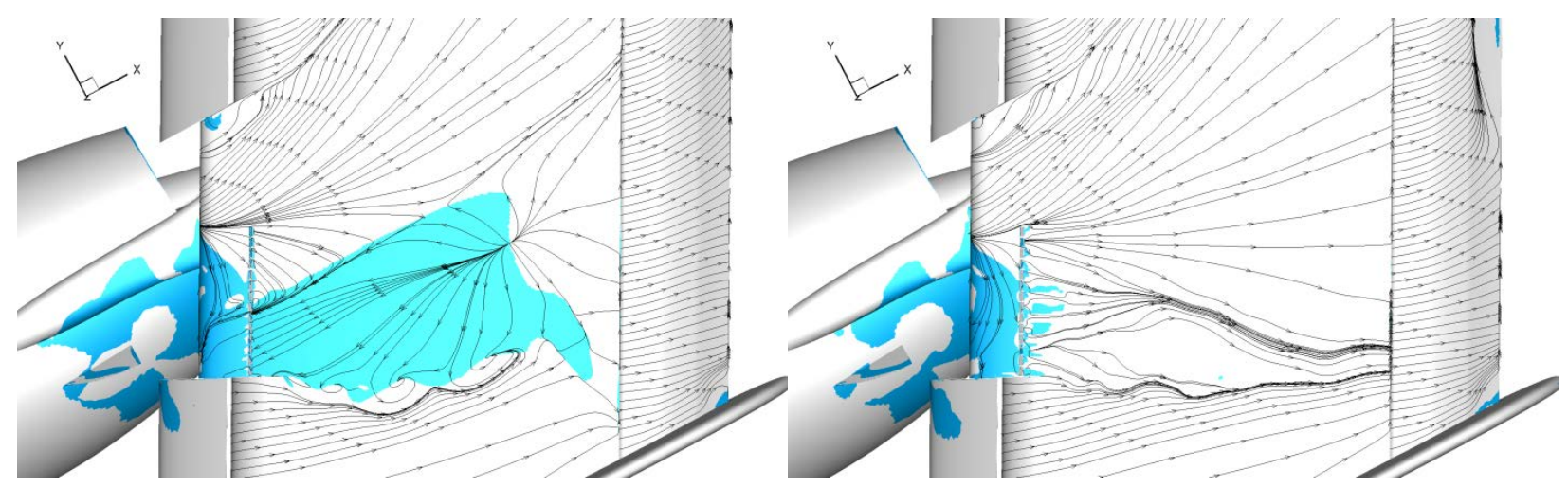

Fig. 18: Active Flow Control applied to the engine-wing junction to prevent early separation past the slat cut-out for the integration of a large engine: (left) without AFC; (right) with pulsed blowing AFC at $v_{j}=272 \mathrm{~m} / \mathrm{s}$. Instantenous snapshots from URANS simulations (images from [34])

Within the scope of the project, this design is currently prepared for a full scale wind-tunnel demonstration test on a $3 \mathrm{~m}$ chord DLR-F15 swept wing model in the TsAGI T-101 wind tunnel. At the end of the project it is intended to have verified the feasibility of the complete AFC installation. It includes the necessary hardware up to a level that allows proceeding towards flight-testing on the DLR-ATRA research test aircraft within future projects.

\section{Multi-Functional Moveables and Multi-Disciplinary Aspects}

In current aircraft most control functions are addressed to dedicated control surfaces. Reminding the early history of high-lift systems, the cambering airfoil of Nayler, Stedman, and Stern had been the foundation for any direct control device like ailerons, elevators, and rudders. It is therefore consequent to think about using high-lift systems for other purposes than for generating high lift coefficients only. Especially, as these systems burden a high level of complexity and weight. So-called multi-functional moveables provide control of the aircraft for more than one purpose. One common example is using the spoiler for roll control. Even at the newest aircraft generation e.g. the high-lift flaps are used to adapt the wing in cruise condition to the actual aircraft weight [35].

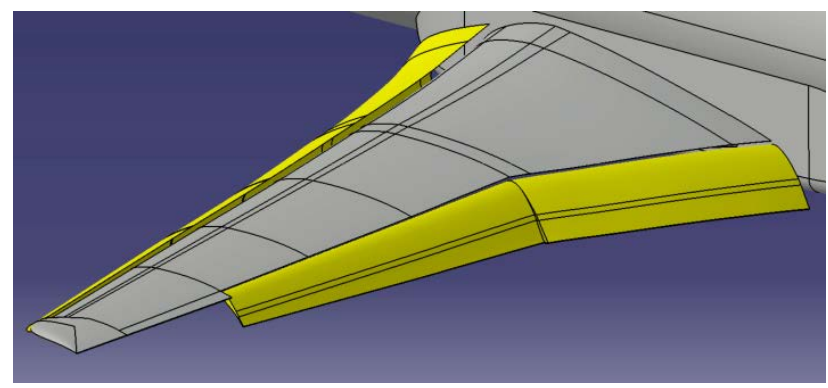

\section{Fig. 19: High-lift wing with differential flap setting}

Such multi-functionality must be evaluated in a multi-disciplinary context.A change of control function imposes impacts on other disciplines, mainly system and kinematics with an additional snowball effect on the weight and cost. And - more important - introducing new functions and corresponding changes in the system architecture allow in addition for new opportunities to adapt the high-lift system.

Current aircraft - with some exceptions - use predefined settings based on the maximum needed performance. The actual high-lift performance requirement is strongly dependent on the actual aircraft condition in terms of real weight and environment conditions. Having a system that can be continuously and differentially adapted to changed conditions can make a benefit to the overall aircraft (Fig. 19). 

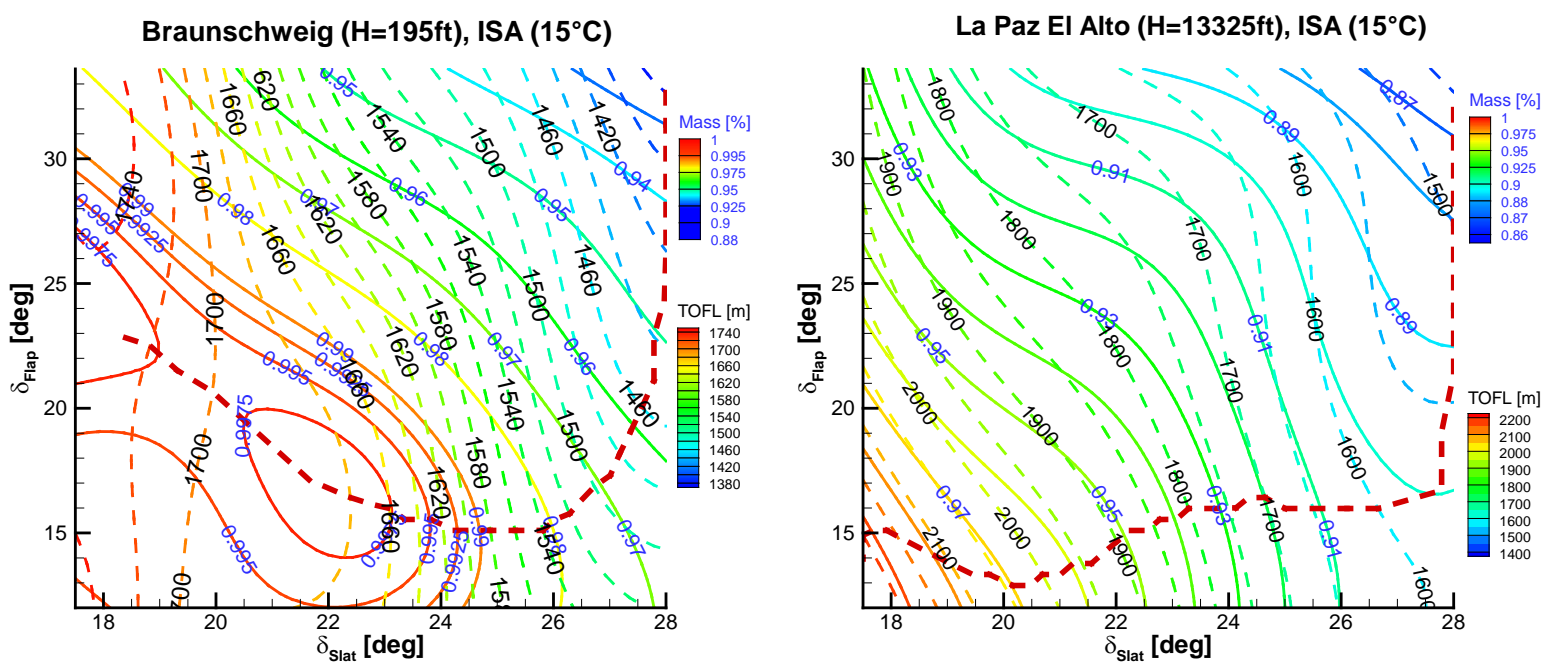

Fig. 20: Optimal continuous high-lift system deflection path depending on aircraft weight and airport elevation; solid contour lines: weight ratio (TOW/MTOW) - dashed contour line: take-off-field length - red dashed line: path for optimal flap deflection for shortest TOFL at given weight (images from [36]).

In the scope of the national funded project MOVE.ON investigations were made how the high-lift setting of a given aircraft should be adapted based on an existing kinematics to improve the aircraft high-lift performance at off-design conditions [36]. Based on the generic FNG aircraft model, continuous and differential adaptions of the high-lift wing were analyzed in the full aircraft context with regard to achievable runway lengths depending on actual aircraft weight and environmental conditions (hot \& high).

Exemplarily, Fig. 20 shows an analysis of trade-offs of adjusted high-lift device settings depending on the airport elevation on full aircraft level. The figures show this analysis in the coordinate system of the actual device deflections of the leading and trailing edge device for the airports Braunschweig (low elevation) and La Paz (high elevation). Isocontour-lines of same take-off field length (TOFL) varying the actual aircraft weight are shown in dashed lines. Isocontour-lines of same aircraft weight (in the ratio of actual weight to maximum weight) while the TOFL varies are shown in sold lines. The optimum setting of the high-lift system is when for a specific weight the minimum field length is obtained or for a given take-off field length the weight is maximum. These settings are derived from the diagram where the iso-lines of both views touch each other. The red dashed lines in the diagrams show the so derived optimum device setting combinations.

Commonly it can be seen, that for very low aircraft weights, a take-off with fully deflected flaps offers the shortest TOFL requirement. With increasing aircraft weight it is first better to reduce the flap setting, while keeping a high slat angle. This keeps the take-off velocity low while increasing the ground acceleration. When getting closer to maximum weight, the slope changes depending on the aircraft altitude. While at low elevation the flap deflection can be slightly increased again, at high elevation the low drag during ground roll must be sustained due to less engine power. The TOFL can be reduced up to 5\% at given aircraft weight or the weight can be increased up to 3.5\% for a given field length when adjusting the high-lift setting in comparison to the fixed take-off setting,

Such investigations show that getting the final performance improvements even towards fine tuning of device settings needs a more global evaluation on aircraft level to cover the different influencing factors including snowball effects properly. Being able to specifically design high-lift systems in close relation to the overall aircraft performance by applying multi-disciplinary optimization will be a key technology for the future.

\section{Summary}

Facing nearly 100 years of high-lift systems, there are still a number of topics to be investigated in the area of high-lift aerodynamics. Nowadays, the focus is more shifted to gain as most as possible form new technologies, to enable new technologies, and to react on new challenges arising from the overall field of air transportation. The contribution gave a summary of recent research streams in the areas of simulation, design and application.

Validating simulation methods is an ongoing task. Especially the area of maximum lift prediction is still challenging. Obtaining high quality validation data from flight and wind tunnel test as shown within HINVA is similarly important as fair comparison of simulation technologies. Not surprisingly, grid generation and turbulence modelling are still a key topic for numeric simulation of high-lift flows to be further addressed.

High-lift systems have a substantial role for enabling laminar flow wing technology. As shown, proper design of compatible high-performance Krueger devices raise the potential of avoiding wing area increase for low-speed purposes. The recent design work performed in the projects DeSiReH and AFLoNext verified the feasibility of such 
devices also in terms of mechanical integration into the very limited space of the leading edges of NLF and HLFC wings.

As noise reduction of high-lift systems has only limited value on its own, performance degradation has to be excluded when developing silent high-lift devices. Balancing aerodynamic and aeroacoustics behavior is here a key to success. Concepts like the VLCS slat device developed in the LEISA and SLED projects show that a reduction of 50\% of the slat generated noise is possible without performance degradation.

Active flow separation control is taking a new step towards application on transport aircraft by focusing on local areas. Preventing flow separation in dedicated areas where other means of high-lift systems are impossible has now proven to be efficiently realizable. Studies performed in the projects MOVE.ON and AFLoNext show successful flow separation prevention within the restrictive limits in terms of energy and mass consumption set by industry. Coming wind tunnel and flight tests will further mature the full integration and applicability.

The biggest challenge nowadays is that high-lift system aerodynamics and design cannot be viewed anymore as a single self-standing discipline. The interaction with other disciplines, as there are structures, kinematics, and systems, have to be respected in much more detail, either by respecting them as constraints during the design or by performing directly multi-disciplinary design and optimization on overall aircraft level. Exemplarily, the analysis of adapted high-lift system settings for off-design conditions within the MOVE.ON project shows a significant potential of up to $5 \%$ for improving existent high-lift system performance in terms of take-off behavior.

\section{Acknowledgements}

The project DeSiReH was funded by the European Commission (EC) under Grant Agreement ACP8-GA-2009-233607. The project AFLoNext is funded by the EC under Grant Agreement ACP3-GA-2013-604013. The project SADE was funded by the EC under Grant Agreement ACP7-GA-2008-213442. The German Ministry of Economics BMWi has funded the projects M-Fly/AeroNext (FKZ 20A0603F), MOVE.ON (FKZ 20A1101B) and HINVA (FKZ 20A0904A) within the frame of the $4^{\text {th }}$ Luftfahrtforschungsprogramm.

The author wants to thank all the unnamed contributors to the mentioned projects, especially Vlad Ciobaca, Dirk Franke, Sebastian Fricke, Anna Gebhardt, Thomas Grund, Markus Kintscher, Timo Kühn, Michael Pott-Pollenske, Ralf Rudnik, and Peter Scholz.

\section{References}

[1] Prandtl, L.: „Über Flüssigkeitsbewegung bei sehr kleiner Reibung“, in: Verhandlungen des III. Internationalen MathematikerKongresses Heidelberg 1904, Teubner, Leipzig, 1905.

[2] Nayler, J.L., Stedman E.W., Stern, W.J.: "Experiments on an Aerofoil having a Hinged Rear Portion." Aeronautical Research Committee (ARC). Reports and Memoranda (R \& M) 110. 1914

[3] Lachmann, G.: "Unterteilte Flächenprofile und ihre Bedeutung für die Flugtechnik“, Dissertation, Technische Hochschule Aachen, 1923.

[4] Handley Page, F.: “Wing and Similar Member of Aircraft”, US patent 1.353.666, 1920.

[5] Fowler, H.D.: “Aerofoil”, US patent 1.670.852, 1927

[6] Bölkow, L.: „Tragflügel mit Mitteln zur Veränderung der Profileigenschaft“, Patentschrift Nr. 694916, Reichspatentamt, 1939.

[7] Krüger, W: „Über eine neue Möglichkeit der Steigerung des Höchstauftriebes von Hochgeschwindigkeitsprofilen“, AVABericht 43/W/64, 1943.

[8] Smith, A.M.O.: High-Lift System Aerodynamics, Journal of Aircraft, Vol. 12, No. 6, 1975, pp. 501-530.

[9] European Commission (pub.): "European Aeronautics: A Vision for 2020”, Office for Official Publications of the European Communities, 2001.

[10] European Commission (pub.): “Flightpath 2050 - Europe’s Vision for Aviation”, Publications Office of the European Union, 2011.

[11] Rumsey, C.L., Slotnick, J.P.: “Overview and Summary of the Second AIAA High Lift Prediction Workshop”, 52 ${ }^{\text {nd }}$ Aerospace Sciences Meeting, AIAA Paper 2014-0747, 2014.

[12] Rudnik, R, Schwetzler, D.: "High lift INflight VAlidation (HINVA) - Overview about the 1st Flight Test Campaign”, $32^{\text {nd }}$ AIAA Applied Aerodynamics Conference, AIAA Paper 2014-2843, 2014.

[13] Walker, F., Dambowsky, F., Girensunlu, E.: "Langsamer, leiser, leichter: Luftfahrtforschungsprojekt HINVA“, DLR (CC-BY3.0) 2015, video available on http://www.dlr.de.

[14] Bier, N.F., Rudnik, R., Quest, J., Schulz, M.: „Stall Behavior of the HINVA KH-A320-HA Highlift Model in ETW”, 53d AIAA Aerospace Science Meeting, AIAA paper 2015-1226, 2015.

[15] Rohlmann, D., Keye, S.: „Stall Maneuver Simulation of an elastic Transport Aircraft based on Flight Test Data“, $33^{\text {rd }}$ AIAA Applied Aerodynamics Conference, AIAA paper 2015-2570, 2015.

[16] Strüber, H., Wild, J.: "Aerodynamic Design of a High-Lift System Compatible with a Natural Laminar Flow Wing within the DeSiReH Project,” 29th Congress of the International Council of the Aeronautical Sciences, 7.-12. Sep. 2014, St. Petersburg, Russia. ISBN 3-932182-80-4, 2014.

[17] Boeing Commercial Airplane Group: "High Reynolds Number Hybrid Laminar Flow Control (HLFC) Flight Experiment - II. Aerodynamic Design”, NASA CR 209324, 1999.

[18] Rudnik, R., Germain, E.: "Re-No. Scaling Effects on the EUROLIFT High Lift Configurations”, 45th AIAA Aerospace Sciences Meeting and Exhibit, AIAA Paper 2007-0752, 2007.

[19] http://www.aflonext.eu 
[20] Wild, J.: "Krüger design for an HLFC wing", $5^{\text {th }}$ CEAS Air and Space Conference, 2015.

[21] Franke, D.M., Wild, J.: “Aerodynamic Design of a Folded Krüger Device for a HLFC Wing”, 19. DGLR-Fachsymposium der $S T A B, 2014$, accepted for publication in "New Results in Numerical and Experimental Fluid Mechanics X", Notes on Numerical Fluid Mechanics and Multidisciplinary Design, Springer, Heidelberg.

[22] Dobrzynski, W., Pott-Pollenske, M.: "Slat Noise Source Studies for Farfield Noise Prediction", 7th AIAA/CEAS Aeroacoustics Conference, AIAA Paper 2001-2158, 2001.

[23] Wild, J., Pott-Pollenske, M., Nagel, B.: “An integrated design approach for low noise exposing high-lift devices”, $3^{\text {rd }}$ AIAA Flow Control Conference, AIAA Paper 2006-2843, 2006.

[24] Pott-Pollenske, M., Wild, J., Bertsch, L.: “Aerodynamic and Acoustic Design of Silent Leading Edge Devices”, 20 ${ }^{\text {th }}$ AIAA/CEAS Aeroacoustics Conference, AIAA Paper 2014-2076, 2014.

[25] Pierce, D., Treadgold, D.: “A Simple Mechanical System to Vary a Wing Section Shape to Suit Various Flight Conditions.” RAE Technical Memorandum (TM) Aero1149,1969.

[26] Pierce, D.: “Fluid Dynamic Lift Generating or Control Force Generating Surface”, US patent 3.716.209, 1973.

[27] Kühn, T., Wild, J.: "Aerodynamic Optimization of a Two-Dimensional Two-Element High Lift Airfoil with a Smart Droop Nose Device”, $1^{\text {st }}$ EASN Association Workshop on Aerostructures, 2010.

[28] Kintscher, M., Monner, H.P., Wiedemann, M., Heintze, O., Kühn, T.: “Design of a Smart Leading Edge Device for Low Speed Wind Tunnel Tests in the European Project SADE”, International Journal of Structural Integrity, Vol. 2, Iss. 4, ISSN 17579864 (2011), pp. 383-405.

[29] Kintscher, M., Monner, H.P., Kühn, T., Wild, J., Wiedemann, M.: “Low Speed Wind Tunnel Test of a Morphing Leading Edge”, AIDAA - Italian Association of Aeronautics and Astronautics XXII Conference, 2013.

[30] Burnazzi, M. Radespiel, R.: “Assessment of leading-edge devices for stall delay on an airfoil with active circulation control”, CEAS Aeronautical Journal; Vol. 5, no. 4, 2014, pp. 359-385.

[31] Wild, J.: "Mach-, Reynolds- and Sweep Effects on Active Flow Separation Control Effectivity on a 2-Element Airfoil Wing", in: Active Flow and Combustion Control 2014, Notes on Numerical Fluid Mechanics and Multidisciplinary Design, Vol. 127. Springer Verlag, ISBN 978-3-319-11966-3, 2014, pp. 87-100.

[32] Ciobaca, V., Wild, J.: "Active Flow Control for an Outer Wing Model of a Take-off Transport Aircraft Configuration - A Numerical Study”, 32 ${ }^{\text {nd }}$ AIAA Applied Aerodynamics Conference, AIAA Paper 2014-2403, 2014.

[33] Ciobaca, V., Wild, J., Bauer, M., Grund, T., Hühne, C.P., Scholz, P., Stefes, B.: „Wind Tunnel Experiments with Active Flow Control for an Outer Wing Model“, 33 ${ }^{\text {rd }}$ AIAA Applied Aerodynamics Conference, AIAA Paper 2015-2728, 2015.

[34] Fricke, S., Ciobaca, V., Kröhnert, A., Wild, J., Blesbois, O.: “Active Flow Control applied at the Engine-Wing Junction”, $5^{\text {th }}$ CEAS Air and Space Conference, 2015.

[35] Reckzeh, D.: "Multifunctional Wing Moveables: Design of the A350XWB and the Way to Future Concepts", $29^{\text {th }}$ Congress of the International Council of the Aeronautical Sciences (ICAS), 7.-12. Sep. 2014, St. Petersburg, Russia. ISBN 3-932182-80-4, 2014.

[36] Franke, D.M.: "Investigation on continuously deflectable High-Lift Devices for a 3D High-Lift Configuration", 33 ${ }^{\text {rd }}$ AIAA Applied Aerodynamics Conference, AIAA Paper 2015-2258, 2015. 